\title{
9. What Kind of Art Is the Cinema of Interactions?
}

\author{
François Jost
}

\begin{abstract}
"What kind of art is the cinema of interactions?" This title promotes the concept of interaction; the intention is therefore to analyze "a work that presents itself as openly interactive: BANDERSNATCH" (2018), a part of the science-fiction anthology series BLACK MirRor. With the help of Goodman and Genette, François Jost develops two major concepts previously coined by the former - autography and allography - to help answer the question as to whether the opposition between film and TV series has to do with differences in artistic quality, a debate exacerbated by Netflix's candidacy at film festivals. Using also a comparison with music partitions, Jost wonders whether the viewer of the interactive work may be called an operator, performer, player, or interpreter.
\end{abstract}

Keywords: Science-fiction, Netflix, contemporary music

It may seem surprising that, in order to define cinema in the digital age, several researchers look for heuristic analogies with The Early Cinema (Hansen 1995; Gaudreault and Marion 2013; Grusin 2016). At first glance, what do those ghost-like characters appearing on flickering filmstrips have in common with images and digital projections without the slightest rough patch, no scratches when the reels start turning and no crackling of the soundtrack, things we got used to over the decades? Nothing or almost nothing. Moreover, Grusin points out, it is not on an aesthetic level that we must make a connection between the beginning and what some see as an end, but the description of the historical process that has affected them both. Commenting on Myriam Hansen's argument, according to which "the early cinema remediated the format of early commercial entertainment

Chateau, D., and J. Moure. Post-cinema: Cinema in the Post-art Era. Amsterdam: Amsterdam University Press, 2020 DOI 10.5117/9789463727235_CHO9 
like vaudevilles and travelling shows" (Hansen 1995, 38-39), he states that "we can see an analogous perceptual continuum in today's digital cinema of interactions between the film screened in the theatre and its multiple remediation in DVDs, video games, trailers, web sites, and so forth" $(2016,70)$.

It is undeniable that the beginning of cinema is linked to various entertainment genres, in the same way as post-cinema. To say that the two are similar is, however, another matter. The likeness does not apply to the two of them, but to the method of approach. While using a much looser understanding of "remediation" than that of the book co-written with Bolter, he simply notes that what others call "intermediality" is the necessary breeding ground for an emerging new medium. Television was first seen as an extension of cinema and radio and, like the Early Cinema, it extended popular entertainment at the time: cabaret, music hall shows and even the circus. However, should we see analogies with post-cinema? I do not think so. On the other hand, the terminus a quo is not uninteresting if we compare it to the terminus ad quem represented by post-cinema, not as one would do with two states, but rather with two paths. I am thus going to start from the beginning of cinema, but in order to follow a completely different path, which I cleared just before the Web 2.o happening. Following in the footsteps of Goodman ([1968] 1990) and later Genette (1994) in the debate on the status of artwork, I have shown how, from a diachronic perspective, this status, far from being fixed once and for all, evolves between the two poles that Goodman calls autography and allography (Jost 2000).

\section{The Return of the Repressed}

At the turn of the nineteenth and twentieth centuries, film is firstly characterized by its performance aspect and thus by its autography. It is accompanied or not by the commentary of a smooth talker, a piano or a sound effects machine, songs sung by the audience, etc. It may be said to differ according to the venue and the day of the week: the spectators do not all see the same object. However, over the years and decades, everything was done to reduce this diversity, confirming Goodman's hypothesis that all the arts were originally autographic, and were gradually and unequally "emancipated" by adopting notation ${ }^{2}$ systems where possible.

1 "We have adopted the word [remediation] to express the way in which one medium is seen by our culture as reforming or improving upon another" (Bolter and Grusin 2000, 59).

2 The reformulation is by Genette $1994,154-156$. 
Since its inception, cinema has acquired techniques that can be said to have continuously reduced the part played by the autographic author, demonstrating a continuous effort to transform the film into a score. ${ }^{3}$ The introduction of cardboard signs in the first decade of the twentieth century did not create verbal narrative - before, that would have been the smooth talker's job - but it laid down the text, which, from then onward, would be the same for all spectators, wherever they would see the film. Similarly, "talking" cinema did not introduce sound, which already existed in so-called "silent" cinema, either through musical accompaniment, sound effects or even certain attempts to synchronize living speech; it only ensured the circulation of the same score. Film music is associated with this movement toward homogenization since, instead of being left to the judgment of a pianist in the theater, it becomes an auctorial choice that makes it intangible.

Since its inception, therefore, cinema has acquired techniques that may be said to have continuously reduced the share of the autographic author (the smooth talker, the sound-effects engineer, the accompanist) by gradually developing film notation systems. From this perspective, digital technology would be the ultimate outcome of this allographic reduction: the almost immaterial work can circulate independently of its medium. In 2000, I wrote that these digital characters would certainly influence the economic structures of cinema. We are there now. However, with hindsight, what seems to me to be the most important thing in this continuous process of allographic reduction, is that we have reached a point where film has become the same for everyone. Even the scratches I spoke about above, which appeared during the screenings and gradually worsened, differentiating the copies of new releases from those shown in small provincial cinemas, have disappeared. The same applies to color calibration defects or other similar material aspects. Digital projection leveled out the differences - until the moment when the spectator took control. As we have just seen, throughout the twentieth century, the variations of the work were on the side of the author or the performance of the work. With digital technology, the viewer can modify the work, first by intervening in the audio-visual parameters (colors, contrasts, sound intensity, etc.), then by influencing the course of the story. These actions almost constitute what could be called the return of the repressed, prompted by allographic reduction brought about by the history of cinema. This is why, in this text, I will consider that the characteristic of post-cinema is interaction.

3 An early twentieth century critic explains this effort as follows: "Cinematography is a form of notation by image, as arithmetic and algebra are notations by figures and letters," Louis Haugmard, Le Correspondant, May 25, 1913 (qtd. in Abel 1993). 
It is also the position of Grusin who, patterning himself on the type of attraction cinema conceptualized by Gunning (1986), defines post-cinema as a "cinema of interactions." For him, the interaction is defined both by its relationship "with other (primarily) digital media" and by its "aesthetic sense in which we find ourselves faced with a cinema of interactions - the emergence of a visual style and narrative logic that bear relationship to digital media like DVDs and video games rather than to that of photography, drama, or fiction" (Grusin 2016, 73).

The opposition between digital media and photography, drama and fiction is a blend of heterogeneous criteria. DVD is a medium that accommodates both recent films and silent classics. As a system for reproducing reality, photography, digital or otherwise, still has a pre-eminent role in cinema. Fiction, on the other hand, is a horizon that cannot be surpassed by any work of invention. As for drama, it is one genre among others that we don't see being shunned by the cinema of interactions. More convincing to me is Greenaway's definition that states, "Cinema must now become an interactive multimedia art form [...]. We are forced to confront this new medium that will make Star Wars look like a candlelight reading in the sixteenth century"(qtd. in Ferenczi 2007; my translation).

\section{Post-cinema or Post-television?}

Instead of defining the cinema of interactions by means of oppositions which are in fact not so, it seems much more fruitful to me to test the concept by analyzing a work that presents itself as openly interactive: BANDERSNATCH (2018). The imprecision of my qualification (a "work") puts a question I had thrown out back on the table, namely the definition of "post-cinema." What is BANDERSNATCH, indeed? As a first approximation, the following minimal definition can be given with confidence: an audio-visual object or product accessible on a SVOD platform, Netflix. This formulation is enough to exclude it from the domain of cinema by those who consider that the latter is firstly and solely defined by its place of appearance, as claimed by Bellour on the back cover:

The screening of a film in a cinema, in the dark, the prescribed time of a more or less collective session, has become and remains the condition of a unique experience of perception and memory, which defines its viewer and which any other viewing situation alters more or less. And that alone is worth being called "cinema." (Bellour 2012, back cover) 
Any other filmic event would be a degraded version. I will come back to this implicit valuation of the traditional projection system, but first, let us continue the investigation into the nature of this mystery object. Wikipedia informs interested parties that "BLACK MIRROR: BANDERSNATCH is a 2018 interactive film in the science fiction anthology series BLACK MIRROR." Film and series at the same time, BANDERSNATCH is therefore halfway between two universes often conceived as opposing; cinema and television. Post-cinema or post-television? Critics are hesitant. Some insist on the serial filiation linking it to BLACK MIRROR, others on the filmic experience. The awarding of prizes confirms this hesitation. BANDERSNATCH was honored with a 2014 British Academy Television Award as Best Dramatic Telefilm. In 2019, BANDERSNATCH received an Emmy Award in the "Outstanding Television Movie" category which, as a genre, brings it between film (Movie) and television; for a BAFTA Television Award in the "Drama" category, which clearly places it on the side of television and in a category much more difficult to relate to one of these two universes, "Outstanding Creative Achievement in Interactive Media Within a Scripted Program.” Finally, BANDERSNATCH received a Golden Trailer Award as "Best Drama/Action Poster for a TV/ Streaming Series." This designation reflects one last difficulty: talking about TV series; whereas today, although formally close to what television has accustomed us to see, they are rather produced by streaming platforms.

This discussion on the generic identity of an audio-visual object is not a simple matter of ontology. It is not so much a question of finding a definitive answer as noting that the answer given to this question also triggers a debate on the artistic status of this object. Spielberg's opposition to the presence of Netflix films at the Oscars testifies to this: "From the moment you commit to televisual format, you make television films. If it's a good film, you certainly deserve an Emmy, but not an Oscar."4 The idea that any filmic event other than a cinema screening is a degraded version leads to an aporia that is perfectly exemplified by RomA's (2018) fate. As we know, in 2016, the Cannes Film Festival selected two Netflix productions, OKJA, by South Korean director Bong Joon-ho, ${ }^{5}$ and The MeYerowitz Stories, by American director Noah Baumbach. This was immediately followed by a huge protest movement by producers and distributors, who criticized the fact that these films would not be released in theaters.

In France, regulations prohibit a film that has been shown in cinemas from being offered on a Netflix type of service before three years have 
elapsed; the platform refuses this obligation, which would deprive its French subscribers of the films in question. In 2018, the question arose once more with RomA, which, for the same reason, was excluded from selection for the Cannes Film Festival. A few months later, the film received the Golden Lion at the Venice Film Festival, followed by the Oscar for Best Film. In response to Spielberg, the platform announced that his films would henceforth be screened in Californian cinemas for a few days before putting them on their website. What is the status of a film like Roma in this context: is it cinema when it is screened in cinemas, not cinema when it is on the platform and, nevertheless, hailed as the best film of the year? Clearly, the criterion of release is theaters is not so much an attempt to differentiate between the arts and the media as an axiological hierarchy - and the nostalgia of a film buff who sorts out the sheep from the goats, in this case cinema as art and television as media.

Determining whether BANDERSNATCH is a film or a series and whether this series is televisual or streaming thus involves an a priori artistic evaluation. All you have to do is listen to the Director of the Cannes Film Festival, Thierry Frémaux, who declares, "Series are industrial and films are poetry." Moreover, there is agreement between the zealots and the denigrators of the series. To establish the artistic status of the series, they will look for works that elevate them to the rank of Quality TV. Like Jane Feuer, who states, "SIX FEET UNDER is highly serialized, uses multiple storylines and an ensemble cast, but it too identifies stylistically with the non-televisual genre of European art cinema. This greater structural reliance on cinema is obvious from the opening credits" (Feuer 2007, 150). This reference to cinema to define "the HBO not TV series" inevitably leads to comparisons with filmmakers considered not just as directors but as authors in their own right. Thus, the same Jane Feuer writes that the dream sequences in Six FeEt Under evoke Fellini (145).

Practically speaking, these two approaches, by seeking to enhance the status of their object - cinema for the one, television for the other - fail to see what brings it closer to one or the other art and that which is not found in the object itself, but in the viewer's gaze. Because, when faced with those series that seem to take to streaming, there are two possible attitudes: either to consider it as a continuation of television - strictly speaking, post-television - or to consider it as a continuation of cinema, post-cinema.

6 See https://www.francetélévisioninfo.fr/culture/cinema/festival-de-cannes/les-series-c-estde-la-production-industrielle-la-remarque-du-delegue-general-du-festival-de-cannes-enerveles-internautes_2742507.html. 
The first attitude consists in playing the series-game or, more exactly, the soap-opera-game. While the channels asked their viewers to wait for the next episode for a period of time determined by the programmer, the net surfer can space the viewing of two episodes of a time that he determines himself, remaining within the logic of serial broadcasting, which is to gradually deliver the episodes, separating them by a certain period of time. The second attitude, which is that of the binge-watcher, consists on the contrary in watching episode after episode, as many as possible, even an entire season, in a very short time, to get to the end. DVDs and the advent of platforms such as Netflix encourage this practice. The sites of certain channels have adopted the same strategy to compete with them. The result is a kind of long feature film, which, on the one hand, neutralizes the curiosity inherent in the soap opera genre and, on the other hand, puts an end to the temporal community that brings actors and viewers together in soap operas; insofar as, from season to season, they age at the same time. Ultimately, the user chooses to turn the streaming series into a post-cinematographic or post-televisual object. Moreover, this freedom of use is close to being the defining feature of all things post.

Does this mean that "the viewer has become proactive and that audioview has become an action" (Gaudreault and Marion 2013, 183)? Moreover, what action are we talking about here? For Gaudreault and Marion, it is firstly a matter of choosing the device on which a film will be shown, of deciding whether to watch it all at once or not, to watch it at home or elsewhere, etc. Talking about action seems a little exaggerated to me in this case and not very new. The 1980 s viewer could also choose to quench his film thirst by deciding to go to the cinema, or to the video rental company or to watch a tape, then to stop the tape with his remote control, or even fall asleep on the couch during its projection. I find the arguments of those who speak about the spectactor more conclusive. As early as 1999, starting from a reflection on multimedia, a group of academics interested in "the recorded image" proposed this term, which they specified as follows: "Actor of his show (in collaboration with the software installed by the designers), spectator of the effects of his acts: such is the posture of the person who confronts these devices, constantly crossing the next semiotic barrier delimiting the interior (the presentation) and the exterior (the device organizing access)" (Barboza and Weissberg 2006, 17). Here, interactivity is compared to the position of the viewer in relation to a statue whose appearance changes according to whether the viewer comes closer or moves away from it, but without formally changing the work itself. Other terms have been suggested, such as "the interactor," for whom "everything that is going to happen on 
the screen now depends on the decisions, actions and initiatives taken by the subject connected to it, the computer user" (Machado 2007, 142). These definitions certainly strike home, but the definition of the spectator leaves the relationship with the designer-programmer or what we must surely call the author in the shadows, while the first definition relegates him to a parenthesis. What about this relationship, which would be opposed to the "dictatorship of the work which imposes itself on me, at the discretion of the television channel programmers" (Gaudreault and Marion 2013, 192)? This is what I now propose to clarify based on BANDERSNATCH's narratological analysis.

\section{“It's Like TV Online. I Control It."}

The film (or the episode of the BLACK MIRROR series) offers a story in which the user (the most neutral word I can find right now) will have to make choices. However, what choices there are and how they impact on the unfolding of this story is for him or her to find out? To answer this question, I viewed the film several times, taking different paths, while at the same time using the programming flow chart developed by an Internet user after the screening of the film (see the end of this text. It contains some errors, but is very useful). I also watched it in its entirety in automatic viewing, i.e., by letting the machine choose the direction of the story for me. This fruitful journey to understand how it works lasted 45 minutes (half as long as what is announced by Netflix).

The story begins on July 9, 1984. A young man, Stefan Butler, wakes up. It is a big day: he is going to put forward a game project to the Tuckersoft Company, managed by Mohan Thakur, in the presence of a game design expert, Colin Ritman. There are two sequences in succession to get there: breakfast with his father, and a bus ride. Two choices were offered: the first concerns his food (Sugar puffs or Frosties), the second the music he will listen to on his Walkman during the journey. Already during the first five minutes, two very different types of user actions are emphasized: choosing one's cereal is a purely paradigmatic choice that does not involve the story at all, insofar as what Barthes (1966) called the cardinal function remains, whatever it may be. ${ }^{7}$ Only what he called catalyses changes, i.e., those details

7 "For a function to be cardinal, it is sufficient that the action to which it refers opens (or maintains, or closes) a significant alternative for the rest of the story, in short that it opens or concludes an uncertainty; if, in a fragment of a story, the telephone rings, it is also possible that 
that embellish the story without changing its direction. Another item to be included in the same file, is the choice between "biting your nails or scratching your ear" when it comes to expressing Stefan's anguish when consulting his psychoanalyst. Alternatively, opting to "bury the body" (of his father) or "cut it into pieces." Whatever the choice, it does not change the narrative structure that the narrator-programmer wants to convey. Even more simplistic is the choice concerning "More action": Yeah or Fuck Yeah. As for the choice of music, it has only an aesthetic consequence without affecting the narrative structure. It cannot be denied, of course, that the repercussion of these decisions on the image tape - we see the father giving the package indicated by the son, the music cassette decided on by the user - prompts a feeling of power and temporary satisfaction, even freedom.

The first possible change of direction comes when Stefan meets Mohan Thakur and developer Colin Ritman. Tuckersoft's boss accepts his project and asks him if he wants to work in the company or at home. Accept or refuse: the Internet user must reply. It is now a syntagmatic choice since it influences the evolution of the story. If he accepts, we end up with a television sequence in which a game critic gives him o out of 5 . Colin slips to Stefan, "Sorry, man, wrong choice ..." To continue this quest for the implementation of the BANDERSNATCH game, you have to follow Stefan who states, "I'm trying again"... and the story starts again at the very beginning, with the alarm clock ringing, until it catches up with the sequence at Tuckersoft. From now on, he will work from home.

As we can see, the choice offered by Thakur is not a choice. To prevent the story from ending, the user is forced to start from scratch and accept that Stefan works at home. The apparent freedom of choice is therefore curbed by the program, which neutralizes what Genette called the arbitrary nature of the story. To this constraint is added another one, the impossibility of going back if it is not an option proposed by the film.

To pass on the narrative structure, which is necessary to understand the plot, the narrator-programmer has softer means, close to those that have been exemplified by the "nudge" theorists. As we know, the latter consists of making indirect suggestions, without forcing, influencing motivations, incentives and decision-making without giving orders, without ordering

it is answered or not answered, which will inevitably lead the story in two different ways. On the other hand, between two cardinal functions, it is always possible to have subsidiary notations, which agglomerate around one nucleus or another without modifying their alternative nature: the space between 'the phone rang' and 'Bond answered' can be saturated by a host of small incidents or descriptions: 'Bond went to the office, lifted a receiver, put down his cigarette,' etc." (Barthes 1966, 9). 
openly. This is exactly how Stefan's psychoanalyst proceeds. The boy finds himself in his office after his appointment at Tuckersoft. He explains that he preferred to work at home because he does not want to be constantly monitored. Nevertheless, he also feels watched by his father. Faced with his growing anxiety, she suggests that he talks about his mother, as it is apparently the anniversary of her passing. It is up to the user to accept or not. If he refuses, she returns to the attack: "you could learn things ... I ask you again: yes or no." Curiosity is this nudge that pushes the user to go and "make" the boy do what he had refused at first. Once again, the user is forced to follow the path offered to him. For the rest of the story, this passage is essential because it tells us in what circumstances, for which Stefan feels at fault, his mother died. In the event of a persistent refusal, the flashback that developed the details of the accident is skipped and another sequence is started.

The term "bad choice" that we have just encountered actually indicates that the user has made an unnecessary detour. Thus, if he refuses to let Stefan talk to his psychoanalyst about his mother, he is put back on track by the program that forces him to talk about it anyway. There is then a flashback in which Stefan is seen at the age of five, looking for his stuffed rabbit, which will delay the mother's departure from the house. Following this departure, she will board a train that will derail. For this cardinal structure to work, when the question is put to the child, "Are you coming?" the program answers "No," without it being possible to do otherwise. Similarly, "spilling tea on the computer" is a choice that leads to a dead end, a "bad choice" that the program corrects by putting the user back on track by forcing him to go back: there are two TV sets on the screen and you have to choose the other term of the alternative: "answer Dad with a scream." This method is used several times. The reversal can be ordered by an extradiegetic source thanks to the options on offer or those that have been decided upon, without further ado, from within the diegesis by the character who decides to "try again." ${ }^{8}$ The ultimate constraint occurs when

8 In an interview with the Hollywood Reporter, the director of this somewhat out of the ordinary episode invited the audience to be "themselves." "Don't think there's a better way, go your own way," he says. "Otherwise, you'll be paralyzed by the anguish of having to make choices. And don't go back: always go forward.” See https://www.huffingtonpost.fr/2018/12/28/ apres-avoir-vu-toutes-les-narrations-possibles-de-Bandersnatch-il-resume-tout-avec-un-schemaattention-spoilers_a_2362875o/. It is a strange recommendation. Firstly, because you cannot hesitate for long, the choice has to be made in a few seconds, because it cannot be made by the machine alone. Then, because, as I have shown, there are at least two procedures that take the user back, wherever there may be. 
the user chooses to spill tea on the computer and the character refuses to do so ("No!") in the following sequence. A softer process, since it leaves the authority of the narrator-programmer in the shadows.

The user's choices do not in any way disrupt the system of probable primers put in place by the scenario. Indeed, the skill of the program is to distribute the narrative primers in the mandatory "common core" of the first sequences (until the meeting with the Tuckersoft Company). Already in the first shots, Stefan swallows pills, thus anticipating his tormented character which the psychoanalyst will tend by an increase in treatment. He shows his father the book BANDERSNATCH which was given to him by his mother, whom we understand to be dead (why? we would like to know). The author of this book beheaded his wife, an event that will be repeated later. Regardless of the routes taken, these notations may be extended later.

Finally, we must insist on the sense of global architecture that survives whatever happens, illustrating the words of the developer, Colin: "there is a message in every game." If the user is subject to constraints, it is nothing compared to those that weigh on Stefan's character, who fears above all to be watched and who feels more and more controlled. At first, he tells his psychoanalyst that he prefers to work from home to avoid control of the company, that he feels like his father is watching him, going so far as to say "I lose control, as if someone else were making my choices (choosing my cereal, yelling at Dad, listening to the music)." If, during the interview with the shrink, one prefers to follow the meeting with Colin, the paranoia becomes a little more widespread. The developer explains to him that "we pay people to play our loved ones [...] they drug us and film us," that Pac-Man, the 1980 game, is an acronym that means "Program and Control Man." "If you listen, you hear the numbers," he concludes. The only way to continue the story beyond the two ends offered to the user is a sequence where Stefan, as he looks up, shouts, "Give me a sign!" The choice is then between a "branching pathway symbol," inherited from the book on Davies's life, and the Netflix logo. As expected, the automatic route leads to the Netflix option. When this last option is selected, whether you go via "Tell me more" or "Try to explain" - another false choice - you learn that Netflix is a twenty-first century entertainment platform (I remind you that the story takes place in 1984), and that "it's like TV online but I control it."' Stefan complains about being controlled by "someone from the future [...]. All this would be happening to entertain someone." The psychoanalyst points out

9 To explain to Stefan what Netflix is, the following sentence appears on his computer screen: "I am looking at you on Netflix. I make decisions for you." 
to Stefan that in terms of play, there is not a lot of action. The user is then asked to choose between "fight her" and "leap through the window." This is a final thumbing of the nose at the user's illusory freedom; this choice is not a choice because, if we decide to take the second path, the director intervenes on the set and explains to the actor, Mike, who plays Stefan, that this ending is not that of the scenario which she hands him as proof. However, the actor has difficulty accepting it since he identifies with his character. This ending thus leads to a final metalepsis where the actor thinks he is the character.

Let us pause for a moment on the complex relationship between mise en abyme and metalepsis. At the same time, Stefan's feeling of being constantly controlled is a mise en abyme of the novel BANDERSNATCH which, while related to Choose Your Own Adventure literature, claims that we are controlled (a chapter in the book on Davies is called "Mind Control Conspiracy"). But above all, it is a mise en abyme of the mechanism itself, based on communication between the diegetic level of Stefan's story and the reality of the play mechanism, which constitutes a metalepsis understood as the contamination of two levels. Although the novel provides examples of "an extradiegetic narrator [who] suddenly comes into direct contact with one of his diegetic characters" (Cohn 2005, 123), it is more rare for a character to complain about his narrator (I have no example in mind). However, that is what happens in BANDERSNATCH. A fictional being feels controlled by a higher power, (who searches in the upper regions by lifting his head), which he does not identify, but which is recognized by the twenty-first century player, who feels directly targeted! A player who is himself controlled by a programmer. Of course, one thinks of the situation imagined by Borges: "chess pieces that are unaware of being guided by a player, who does not know that he is guided by a god, a god who does not know that he is guided by another god" (1970, 192-193). Except that here, the character feels it instinctively. The director's intrusion on the set and the ensuing confusion between character and actor is, in that sense, a more frequent metalepsis although, in this case, it is decided on several levels. At first glance, as I have just said, we suddenly move from the character to the actor, whose condition worries the director to the point of calling a doctor. In fact, it is an additional illusion, as the credits inform us, since Mike is not the name of the real actor (Fionn Whitehead), but a new diegetic mask.

Let us summarize the rules of the BANDERSNATCH story: it is impossible to go back when you want to, there are paths you are forced to take, there is a suggested global meaning ... The constraints are numerous and the actions are limited by the decisions of the programmer, who does little 


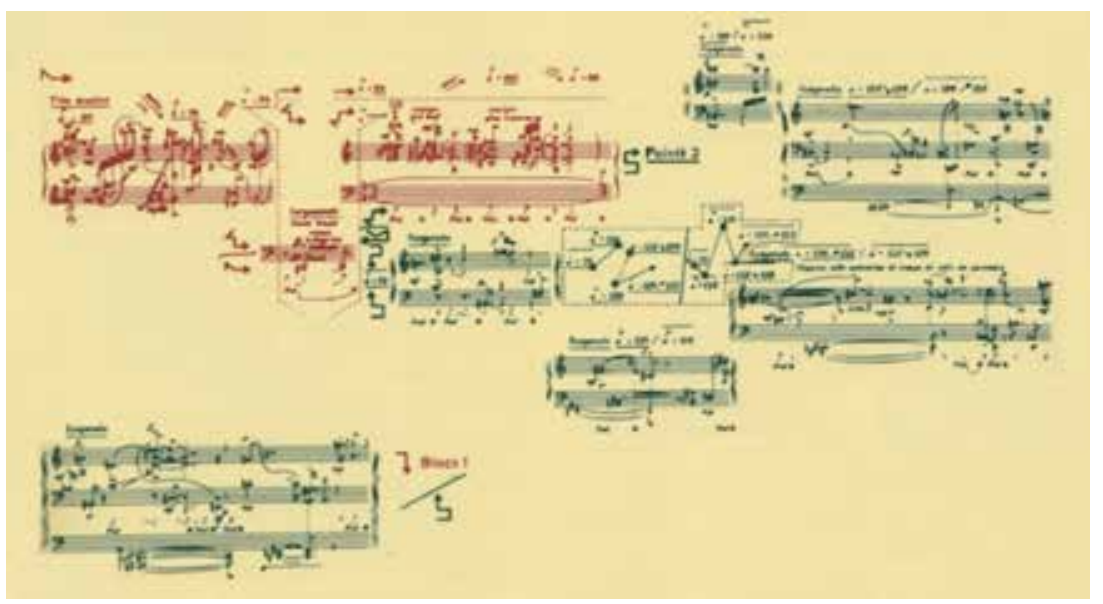

Score of Pierre Boulez's third piano sonata (third movement)

more than develop what is called a "narrative program." "Spectactor" and "interactor" are in fact actors whose actions are largely controlled. It is clear that we must fall back on the freedom of this new user who is placed at an equal distance from the movie viewer and the video game player. Let us say that he is on probation and that, whatever he does, he is carrying out a program that defines his field of action. How must he be characterized when, instead of emphasizing freedom, more emphasis is put on constraint? As we have seen, the supporters of the "spectactor" conceded a temporary reconciliation with the subject, which revolves around a statue. As for me, I prefer to turn to music. This is the meeting-place of all the digressions, the random passages executed or not according to the orders of a higher authority. They can be found, for example, in some of Pierre Boulez's pieces, where certain bars of the score may or may not be played. Take the third movement of his third piano sonata. It looks like this:

Here is how they should be read according to musicologist Dominique Jameux:

These musical fragments appear on the score - made up of 9 sheets paginated from a to i and measuring $39 \times 60 \mathrm{~cm}-$ according to their structural role. Three are green and are called Points; the two in red are Blocks. Points and Blocks, in contrast as the name suggests, are played alternately, with the Points appearing in odd-numbered places. Thus, the fragments written by the composer follow one another in an order left to the performer's choice, knowing that the latter can afford to choose to overlook certain fragments. (Jameux, n.d., n.p.: my translation) 
Isn't this the exact case of the BANDERSNATCH player-spectator? He too will follow the score put together by the programmer, according to an order he has chosen..$^{10}$ We can apply this description to him in the words of the musicologist without hesitation: "The main characteristics of this open form, where the interpreter receives a text which is determined in minute detail, but for which he has a certain freedom of arrangement, will only be summarized in broad strokes."

The agent of this production, also known as a "performer" in music, is neither an author nor an executant, but the "operator" of a project that aims to be anonymous." In addition, Boulez concluded: "If there were any profound motive for the work I have tried to describe, it would be the quest for such 'anonymity."

This comparison allows us to return to our reflection on the opposition between autographic and allographic arts. If, as I said, the history of cinema has shown that, up to and including digital, it bears witness to a constant effort for allographic reduction, the cinema of interaction has a new status, close to contemporary music.

The musician's work, writes Goodman, is "freed of dependence upon a particular author or upon a place or date or means of production"(1968, 195). So many characteristics that could just as easily be applied to postcinema. The score defines his oeuvre, including the optional paths. The performance, from this point of view, is an exemplification of the partition. The BANDERSNATCH user, like the performer of a Boulez piece, chooses to play a course that is part of a very precise scoring system. Just as the listener of the third movement of the third piano sonata is unaware of what has not been played, he has no knowledge of the path he could have taken, until he decides to start his journey again.

If, as a result, spectator or interactor overestimate an unspecified action that goes far beyond what they lead us to imagine, what do I call what has been a user until now? A word combined with "actor" would be possible, provided it were specified that it is more in the sense of an actor who plays a text written by someone else than as an acting actor. Faced with the cumbersomeness it generates, I prefer to dismiss it. Operator, performer, player ... and if this user were simply called an "interpreter?" That would have the advantage of referring both to the musician (performer) who structures part of the work according to his own choices and as a reminder that any spectator, whatever the form of the audio-visual narrative he is considering, 
is always a hermeneut capable of giving meaning, even to what seems to be the most unstructured stories. ${ }^{11}$

To consider the user of a post-cinema film as an instrumentalist who can choose which way to navigate through a score - both in the musical sense and in the sense of a notation system given by Goodman - is to extend his freedom and draw its outlines. It is the ambition of this text: to substitute euphoric and approximate discourses on the transformation of the user of the narrative for a more precise and accurate evaluation of this activity tested by the heuristic virtue of analysis.

\section{Translated by Naòmi Morgan}

\section{References and Further Reading}

Abel, Richard. 1993. French Film Theory and Criticism. A History/Anthology. Princeton: Princeton University Press.

Barboza, Pierre, and Jean-Louis Weissberg, eds. 2006. L'image actée. Scénarisations numériques, parcours du séminaire. L'action sur l'image. Paris: L'Harmattan.

Barthes, Roland. 1966. "Introduction à l'analyse structurale du récit." Communications, no.8:1-27.https://www.persee.fr/doc/comm_0588-8018_1966_num_8_1_1113.

Bellour, Raymond. 2012. La querelle des dispositifs: Cinéma - installations, expositions. Paris: P.O.L.

Bolter, Jay David, and Richard Grusin. 2000. Remediation. Understanding New Media. Cambridge, MA: MIT Press.

Borges, Jorge Luis. 1970. The Aleph and Other Stories. New York: Bantam Books.

Cohn, Dorrit. 2005. "Métalepse et mise en abyme." In Métalepses, edited by John Pier and Jean-Marie Schaeffer. Paris: Éditions des Hautes Études en Sciences Sociales.

Ferenczi, Aurélien. 2007. "Peter Greenaway constate la mort du cinema." Télérama, October 12, 2007.

Feuer, Janet. 2007. "HBO and the Concept of Quality TV." In Quality TV, edited by Janet McCabe and Kim Akass. London: I.B. Tauris \& Co.

Gaudreault, André, and Philippe Marion. 2013. La fin du cinéma? Paris: Armand Colin. Genette, Gérard. 1994. L'œuvre de l'art. Paris: Seuil, Coll. Poétique.

Goodman, Nelson. 1968. Languages of Art. An Approach to a Theory of Symbols. Indianapolis and Cambridge: Hackett Publishing Company, Inc.

11 It is a very difficult word to translate into English; player, which denotes the musicianperformer, is a too obvious reference to the manner of playing without specifying how it functions on a musical level; performer would lose all the nuances I actualized in this text. Instrumentalist? 
Grusin, Richard. 2016. "DVDs, Video Games and the Cinema of Interactions." In Post-Cinema. Theorizing 21st Century Film, edited by Shane Denson and Julia Leyda. Falmer: Reframe Books.

Gunning, Tom. 1986. "The Cinema of Attraction[s]: Early Film, Its Spectator and the Avant-Garde." Wide Angle 8, no. 3-4 (Fall): 63-70.

Hansen, Miriam. 1995. "Early Cinema, Late Cinema: Transformations of the Public Sphere." In Viewing Positions: Ways of Seeing Film, edited and introduced by Linda Williams. New Brunswick: Rutgers University Press.

Jameux, Dominique, and Pierre Boulez. N.d. " 3 ème SONATE POUR PIANO. Formant: Constellation-Miroir.” Education Musicale. Histoires des Arts. http://emusicale. free.fr/HISTOIRE_DES_ARTS/hda-musique/BOULEZ-sonate_pour_piano_n3/_ sonate_pour_piano.php.

Jost, François. 2000. "Convergences du spectateur." La croisée des médias. Sociétés et Représentations, no. 9: 131-141. https://www.cairn.info/revue-societes-etrepresentations-2000-2-page-131.htm.

Machado, Arlindo. 2007. O sujeito na tela: Modos de enounciação no cinema e no ciberespaço. São Paulo: Paulus.

\section{About the Author}

François Jost is Professor Emeritus at the Sorbonne Nouvelle University, Paris 3, where he created the Centre d'Études sur l'Image et le Son Médiatiques (CEISME). He has written or edited more than thirty books on cinema and television and published 150 articles. He is the editor of the collection $\grave{A}$ suivre, devoted to television series at Atlande editions; and the review Télévision (CNRS éditions). His latest books include: Sous le cinéma, la communication (2014); Les nouveaux méchants. Quand les séries américaines font bouger les lignes du Bien et du Mal (2015); Breaking Bad, Le diable est dans les détails (2016); Pour une éthique des médias. Les images sont aussi des actes (2016); La méchanceté en actes à l'ère numérique (2018); and Médias: Sortir de la haine? (Forthcoming). He has also published a novel and directed several short films. 